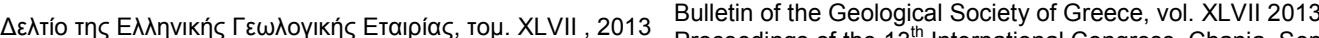

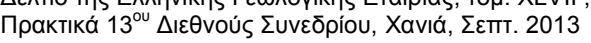

\title{
LOCAL MAGNITUDE ESTIMATION IN GREECE, BASED ON RECORDINGS OF THE HELLENIC UNIFIED SEISMIC NETWORK (HUSN)
}

\author{
Scordilis E. ${ }^{1}$, Kementzetzidou D. ${ }^{1}$ and Papazachos B. ${ }^{1}$ \\ ${ }^{I}$ Aristotle University of Thessaloniki, Faculty of Geology, Department of Geophysics, \\ manolis@geo.auth.gr,dkementz@auth.gr
}

\begin{abstract}
A new relation is proposed for calculation of local magnitudes in Greece. For this purpose, there were used synthetic Wood-Anderson (SWA) recordings of 98 digital broad-band stations operating between 2007 and 2011. These stations are installed at the sites of the seismological networks of: a) the National Observatory of Athens $(H L), b)$ the Department of Geophysics of the Aristotle University of Thessaloniki (HT), c) the Seismological Laboratory of the University of Athens (HA) and d) the Seismological Laboratory of the University of Patras (HP). All these institutions constitute the recently (2004) established Hellenic Unified Seismic Network (HUSN). These recordings are used to calculate a refined geometrical spreading factor and an anelastic attenuation coefficient, representative for Greece and surrounding area, proper for estimating local magnitudes in this region. Individual station corrections are also calculated in order to further ameliorate magnitude estimation accuracy. Comparison of such calculated local magnitudes with corresponding original moment magnitudes revealed that these two scales are equivalent for a wide range of values $\left(2.9 \leq M_{W} \leq 6.4\right)$.
\end{abstract}

Key words: Synthetic Wood-Anderson records, geometrical spreading, anelastic attenuation.

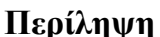

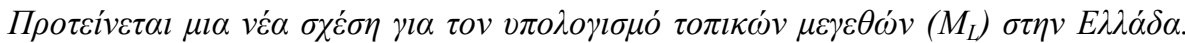

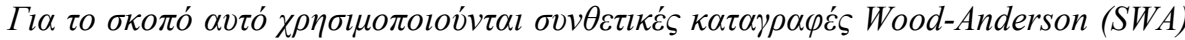

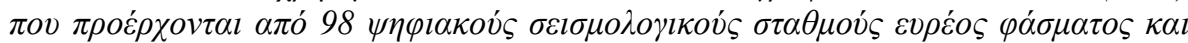

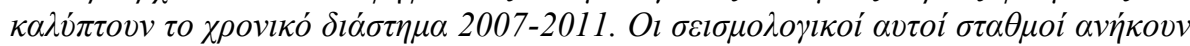

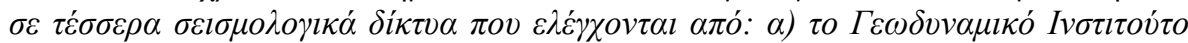

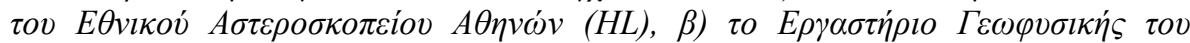

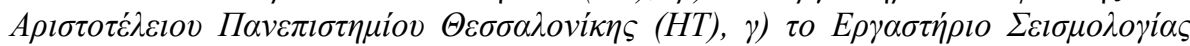

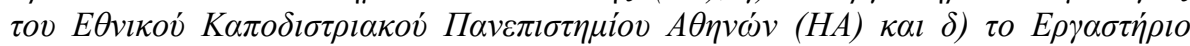

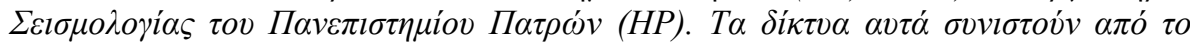

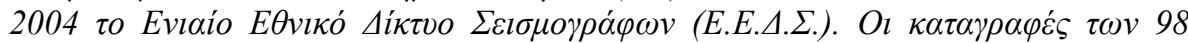

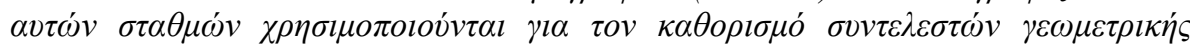

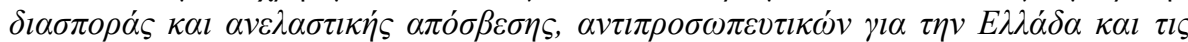

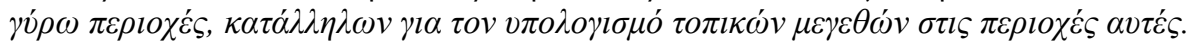

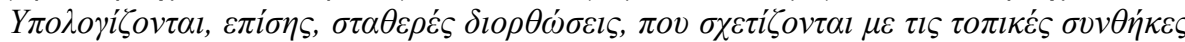

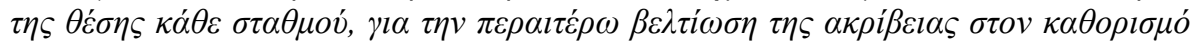

$\underline{\text { XLVII, No } 3-1241}$ 


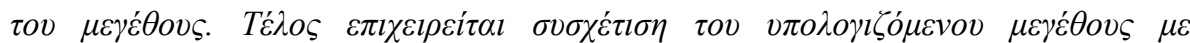

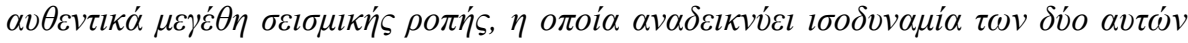

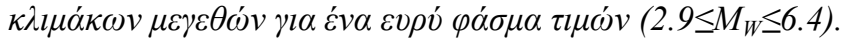

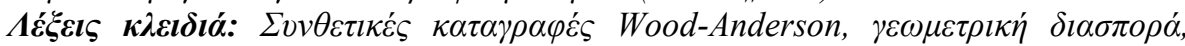

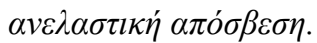

\section{Introduction}

This To measure the "size" of earthquakes, Richter (1935) introduced the local magnitude scale, $M_{L}$, using trace amplitudes of local earthquakes recorded on typical Wood Anderson seismographs with magnification 2,800; natural period 0.8sec; damping 0.8 (Anderson and Wood, 1924, 1925). Recent studies (Uhrhammer and Collins, 1990; Uhrhammer et al., 1996) have showed that the effective magnification of the typical WA seismograph is around 2,080, which means a systematic error in $M_{L}$ estimations. Other magnitude scales $\left(m_{b}, m_{B}, M_{S}, M_{D}\right)$ which were introduced soon after the definition of $M_{L}$ did not overcome the limitations introduced by the instruments' response and the frequency content of the seismic waves. However, the important role of the local magnitude scale in earthquake hazard assessments has been emphasized for years by several workers (Kanamori and Jennings, 1978; Hutton and Boore, 1987; Boore, 1989).

The $M_{W}$ scale (Kanamori, 1977; Hanks and Kanamori, 1979), solved the problem of confusing plurality and limited applicability of the existing magnitude scales. This scale is reasonably reliable since it is controlled by the fault size and dislocation. The robustness of the $M_{W}$ estimation is due to the fact that seismic moment estimation is based on spectral amplitudes. On the other hand, $M_{W}$ does not saturate, since it is directly proportional to the logarithm of seismic moment. As a result $M_{W}$ exhibits a uniform behavior for all magnitude levels. For these reasons, this magnitude is considered as the most reliable earthquake magnitude, because it accurately describes the size of earthquakes and its relation with other magnitude scales has been also accurately defined (Heaton et al., 1986; Johnston, 1996; Shedlock, 1999; Papazachos et al., 2002, Scordilis, 2006).

The relation between $M_{L}$ and $M_{W}$ has been extensively studied by several authors and for different seismotectonic environments (Heaton et al., 1986; Kim et al., 1989; Uhrhammer et al., 1996; Papazachos et al., 1997, 2002; Utsu, 2002; Grünthal and Wahlström, 2003; Brazier et al., 2008). In most of the relative works it is shown that these two magnitude scales are equivalent for a wide range of magnitudes.

In 2002, a working group of IASPEI proposed relations for different scale magnitude estimations. That is, for $M_{L}$ magnitude they adopted a poly-parametric estimation of distance correction by relations of the form of equation 1 where, $A$ is the 0 -peak (in $\mathrm{mm}$ ) amplitude on a typical WA seismograph (recorded or synthesized), $R$ is the hypocentral distance (in $\mathrm{km}$ ), $n$ is the geometrical spreading factor, $K$ is the anelastic attenuation coefficient and $c_{i}$ is a standard correction. This relation was initially proposed by Bakun and Joyner (1984). Especially, for regions with attenuation similar to this of southern California IASPEI proposed the above relation with $n=1.11$ and $K=0.00189$ estimated by Hutton and Boore (1987).

Equation 1 - Formula for for $M_{L}$ magnitude estimation proposed by IASPEI working group.

$$
M_{L}=\log A+n \cdot \log (R / 100)+K(R-100)+c_{i} .
$$

In Greece, a WA seismograph was installed at the seismological station of Athens in 1965. Its records were used for a long time period by HL for regular determinations of local magnitudes in Greece by adopting the calibration function, $-\log A_{0}=f(R)$, of Richter $(1935,1958)$. Kiratzi and Papazachos (1984) used these WA records to define new relations for the estimation of local magnitudes, $M_{L G}$, in Greece and surrounding areas, valid for epicentral distances $100<\Delta \leq 1000 \mathrm{~km}$. They also noticed a possible inconsistency between $M_{L G}$ and $M_{W}$. Kiratzi (1984) and Scordilis

XLVII, No 3 - 1242 
(1985) calibrated the recordings of short period instruments of the HT network for defining relations to estimate magnitudes equivalent to $M_{L G}$ for a wide range of epicentral distances. Papazachos et al. (1997) in searching the relations between $M_{W}$ and other magnitude scales in Greece observed the same inconsistency between the $M_{L G}$ and $M_{W}$. This inconsistency has been confirmed (and extensively discussed) by Margaris and Papazachos (1999) who used strong motion recordings of earthquakes in Greece to estimate typical $M_{L}\left(M_{L S M}\right)$. Papazachos et al. (2002) compared the $M_{W}$ of 329 earthquakes, which occurred in the broader area of Greece during the period 1959-2001, with magnitude scales that are used in Greece (i.e. $M$ from Wiechert and Mainka, $M_{L}, M_{L S M}$ ) confirming the previous results on $M_{L G}$.

For the last 5 years, $M_{L}$ in Greece is estimated by the recordings of the digital broadband stations of HUSN, using the relation proposed by Hutton and Boore (1987) after applying a proper levelcorrection. However, even though this relationship gives better results than in the past, some inconsistencies with $M w$ are still noticeable.

The purpose of this work is to estimate new attenuation parameters (and individual station corrections) better adapted to Greece and surrounding areas, which allow more accurate magnitude determination for the earthquakes of this area.

\section{The Data}

Digital recordings of 98 seismological stations (Figure 1) belonging to the HUSN and operated by its four participants (HL, HT, HP and HA), are used to carry out this study. These recordings correspond to shallow earthquakes (focal depths up to $40 \mathrm{~km}$ ) which occurred in the area bounded by the coordinates $33^{0} \mathrm{~N}-43^{0} \mathrm{~N}, 18^{0} \mathrm{E}-30^{0} \mathrm{E}$ for the time period October of 2007 - end of 2011.

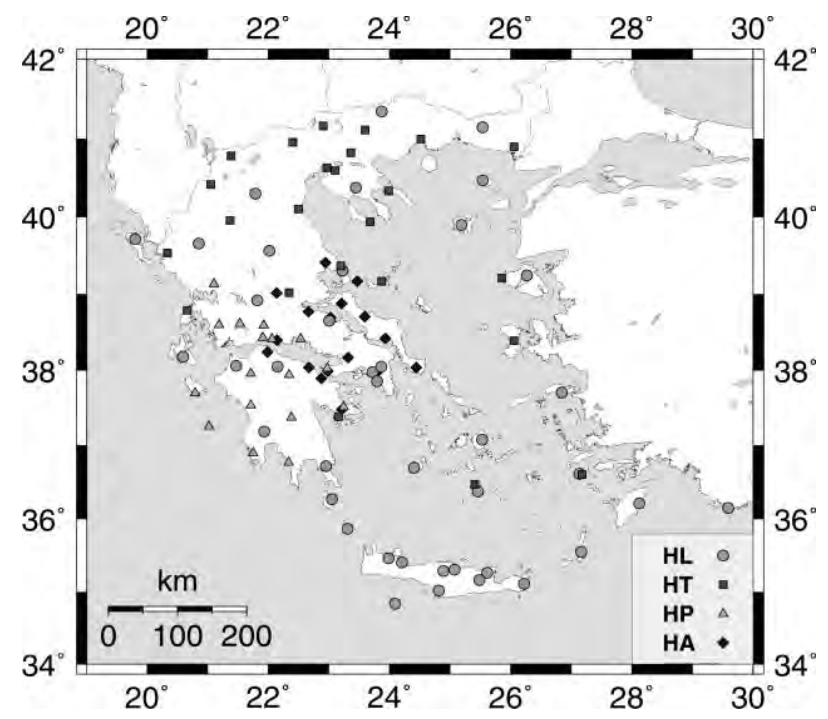

Figure 1 - The 98 stations of the HUSN of which the recordings are used in the present study.

After de-convolving the instrument response of each recording and re-convolving with the WA response, synthetic WA seismograms (SWA) were generated (Kanamori and Jennings, 1978; Bakun et al., 1978; Uhrhammer and Collins, 1990), considering both the instrumentation characteristics of each employed station and the characteristics of the standard WA seismograph $\left(V=2080, T_{0}=0.8 \mathrm{sec}\right.$, critical dumbing 0.8$)$.

For each station and for each earthquake, maximum trace amplitudes were measured on both N-S and E-W SWA components, where it was feasible. The mean amplitude was used to constitute a single measurement that corresponds to each station and each shock, since $M_{\mathrm{L}}$ was originally de- 
fined as a function of the mean maximum trace amplitudes of NS and EW WA components. The finally produced data-base includes a total of 177,234 SWA picks corresponding to 23,354 earthquakes. The epicentral distances of the 98 stations that recorded these earthquakes reach up to 600 $\mathrm{km}$ and their magnitudes range from 2.9 to 6.4 (in the $M_{W}$ scale)..

\section{Method and Results}

Starting with relation 1 and assuming that the frequency independent geometrical spreading factor, $n$, and the anelastic attenuation coefficient for the path (frequency dependent), $K$, should each have

\section{Equation 2 - Calibration function used to fit the available data.}

$$
M_{L}-\log A=n \cdot \log (R / 100)+K \cdot(R-100)+c+d_{i}
$$

the same value for the whole area under study, equation 2 was fitted to the data, where, $A$ is the average 0-peak amplitude (in $\mathrm{mm}$ ) of the two horizontal components of the SWA, $R$ is the hypocentral distance (in $\mathrm{km}$ ), $c$ is a standard correction and $d_{i}$ is an additional level correction due to the site conditions of each station, $i$. In order to define these parameters a reference magnitude was

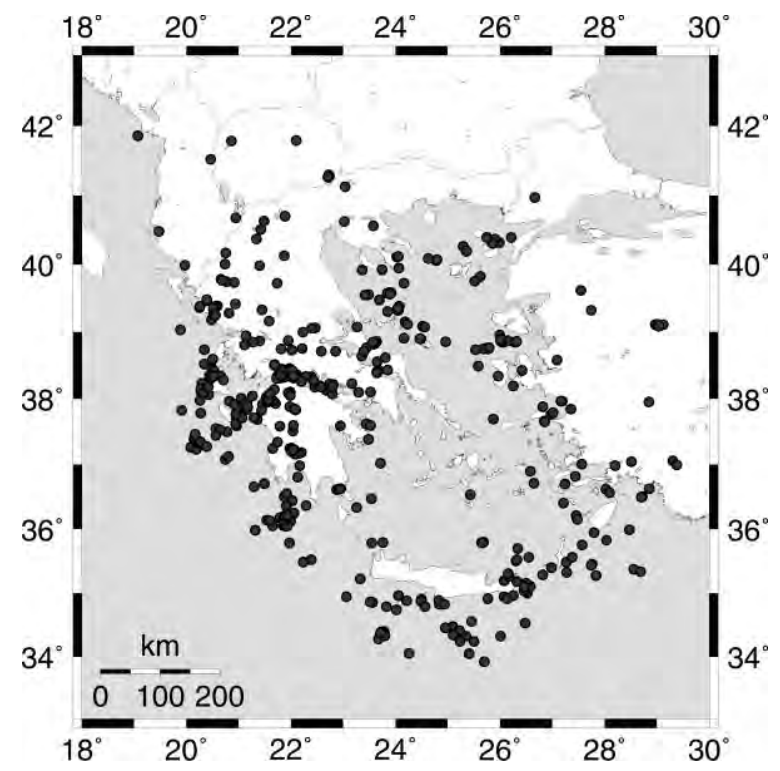

Figure 2 - Epicenters of 453 earthquakes with available $M_{W}$ used in the present study.

necessary. Considering previous studies which confirmed the consistency (equivalence) between $M_{L}$ and $M_{W}$ (i.e. Heaton et al., 1986; Bollinger et al., 1993; Uhrhammer et al., 1996; Utsu, 2002; Brazier et al., 2008) the $M_{W}$ is chosen as such reference magnitude. Several sources (GCMT, NEIC, EMSC, NOA, AUTH, UPSL, NKUA) provided $M_{w}$ values for 453 earthquakes, satisfactorily covering the study area (Figure 2 ).

The data (moment magnitudes, SWA amplitudes and hypocentral distances) were elaborated with the code MINUIT ver94.1 (James, 1998) which is based on the simplex method of Nelder and Maed (1965) and the variable metric method of Fletcher (1970), in order to fit equation 2. The data sample consists of 5270 data points corresponding to mean SWA records of the 473 earthquakes with available $M_{W}$. The derived coefficient-values are $n=1.2614, K=0.0031$ and $c=0.9043$ (Figure $3)$. 


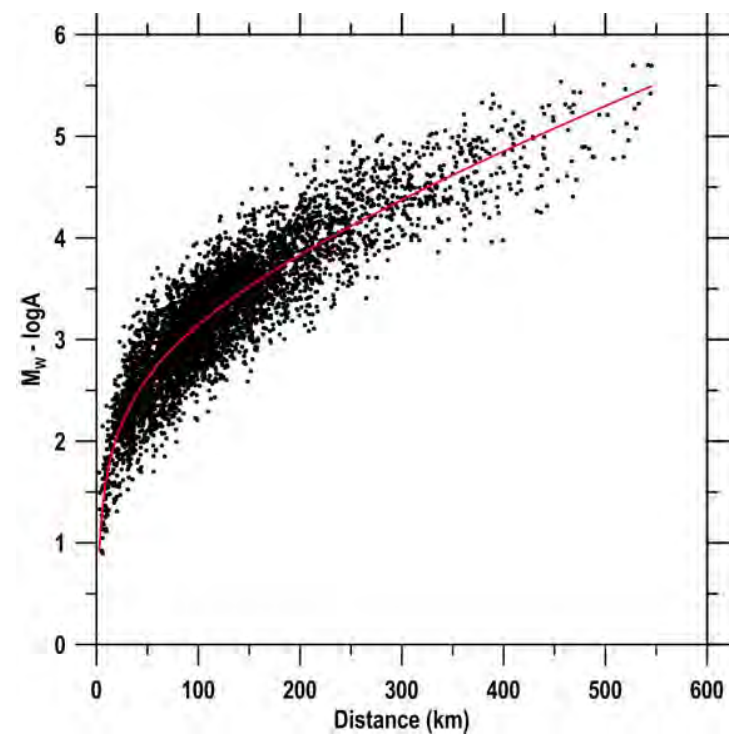

Figure 3 - Calibration function for shallow $(h<40 \mathrm{~km})$ earthquakes. The line represents the best fitting the data curve.

Individual differentiations from $M_{W}$ values have been calculated and used as level-corrections for each station in order to avoid biases related to possible inconsistencies in instruments responses. The procedure has been repeated for defining this way more representative $n, K$ and $c$ values. To further ameliorate the correlation of the estimated magnitude with $M_{W}$, individual correction, $d_{i}$, was estimated for each station, by keeping the $n, K$ and $c$ values and using each station's data separately. Such corrections are attributed to the local conditions of each station. The results for all 98 available stations are shown on Table 1.

Table 1. Station corrections attributed to local conditions.

\begin{tabular}{|c|c|c|}
\hline Net & $\begin{array}{c}\text { Station } \\
\text { Code }\end{array}$ & $\boldsymbol{d}_{\boldsymbol{i}}$ \\
\hline HA & ACOR & -0.1791 \\
\hline HT & AGG & 0.0488 \\
\hline HT & ALN & 0.0910 \\
\hline HP & AMT & -0.2016 \\
\hline HL & ANKY & 0.0740 \\
\hline HP & ANX & -0.1302 \\
\hline HT & AOS & 0.0740 \\
\hline HL & APE & 0.1551 \\
\hline HL & ARG & 0.0038 \\
\hline HA & ATAL & 0.2638 \\
\hline HL & ATH & -0.0863 \\
\hline HA & ATHU & 0.4175 \\
\hline HA & AXAR & -0.3430 \\
\hline HT & CHOS & -0.0804 \\
\hline HT & CMBO & -0.3415 \\
\hline
\end{tabular}

\begin{tabular}{|c|c|c|}
\hline Net & $\begin{array}{c}\text { Station } \\
\text { Code }\end{array}$ & $\boldsymbol{d}_{\boldsymbol{i}}$ \\
\hline HP & DID & -0.0418 \\
\hline HA & DIDY & -0.0081 \\
\hline HP & DRO & -0.2160 \\
\hline HP & DSF & 0.0874 \\
\hline HP & DSL & -0.0285 \\
\hline HP & DYR & 0.1284 \\
\hline HP & EFP & -0.0753 \\
\hline HA & EREA & -0.0227 \\
\hline HL & EVR & 0.0515 \\
\hline HT & FNA & -0.0859 \\
\hline HA & FYTO & 0.2408 \\
\hline HT & GRG & -0.0206 \\
\hline HP & GUR & -0.2064 \\
\hline HL & GVD & -0.1377 \\
\hline HT & HORT & 0.2369 \\
\hline
\end{tabular}

\begin{tabular}{|c|c|c|}
\hline Net & $\begin{array}{c}\text { Station } \\
\text { Code }\end{array}$ & $\boldsymbol{d}_{\boldsymbol{i}}$ \\
\hline HL & IACM & -0.4053 \\
\hline HL & IDI & 0.2022 \\
\hline HT & IGT & 0.1432 \\
\hline HL & IMMV & -0.1219 \\
\hline HL & ITM & 0.0998 \\
\hline HL & JAN & -0.0397 \\
\hline HA & KALE & -0.0236 \\
\hline HL & KARP & -0.0557 \\
\hline HA & KARY & 0.0722 \\
\hline HT & KAVA & 0.0737 \\
\hline HL & KEK & 0.0770 \\
\hline HL & KLV & 0.2570 \\
\hline HT & KNT & 0.1258 \\
\hline HT & KPRO & 0.0368 \\
\hline HT & KRND & -0.0786 \\
\hline
\end{tabular}

\begin{tabular}{|c|c|c|}
\hline Net & $\begin{array}{c}\text { Station } \\
\text { Code }\end{array}$ & $\boldsymbol{d}_{\boldsymbol{i}}$ \\
\hline HL & KSL & 0.1163 \\
\hline HL & KYTH & -0.0315 \\
\hline HL & KZN & 0.0296 \\
\hline HA & LAKA & 0.0622 \\
\hline HL & LAST & 0.1948 \\
\hline HL & LIA & -0.0255 \\
\hline HT & LIT & 0.0672 \\
\hline HT & LKD2 & -0.0201 \\
\hline HL & LKR & 0.0448 \\
\hline HA & LOUT & 0.0922 \\
\hline HP & LTK & 0.0299 \\
\hline HA & MAKR & -0.3116 \\
\hline HL & MHLO & -0.4520 \\
\hline HA & MRKA & -0.0310 \\
\hline HL & NEO & -0.1274 \\
\hline
\end{tabular}

$\underline{\text { XLVII, No } 3-1245}$ 


\begin{tabular}{|c|c|c|}
\hline Net & $\begin{array}{c}\text { Station } \\
\text { Code }\end{array}$ & $\boldsymbol{d}_{\boldsymbol{i}}$ \\
\hline HT & NEST & 0.0261 \\
\hline HT & NIS1 & -0.1998 \\
\hline HL & NISR & -0.0927 \\
\hline HL & NPS & 0.0451 \\
\hline HL & NVR & 0.1136 \\
\hline HT & OUR & -0.0729 \\
\hline HT & PAIG & 0.1837 \\
\hline HP & PDO & -0.3495 \\
\hline HL & PLG & 0.2552 \\
\hline HL & PRK & -0.2960 \\
\hline
\end{tabular}

\begin{tabular}{|c|c|c|}
\hline Net & $\begin{array}{c}\text { Station } \\
\text { Code }\end{array}$ & $\boldsymbol{d}_{\boldsymbol{i}}$ \\
\hline HL & PTL & 0.0252 \\
\hline HP & PVO & 0.0360 \\
\hline HP & PYL & 0.1229 \\
\hline HL & RDO & 0.0863 \\
\hline HL & RLS & 0.2043 \\
\hline HL & SANT & -0.0699 \\
\hline HP & SERG & 0.0203 \\
\hline HP & SFD & -0.3116 \\
\hline HT & SIGR & -0.0494 \\
\hline HL & SIVA & -0.2834 \\
\hline
\end{tabular}

\begin{tabular}{|c|c|c|}
\hline Net & $\begin{array}{c}\text { Station } \\
\text { Code }\end{array}$ & $\boldsymbol{d}_{\boldsymbol{i}}$ \\
\hline HA & SKIA & -0.0694 \\
\hline HL & SMG & -0.1667 \\
\hline HA & SMIA & -0.4173 \\
\hline HL & SMTH & 0.0625 \\
\hline HT & SOH & -0.0077 \\
\hline HT & SRS & 0.2114 \\
\hline HA & THAL & -0.3020 \\
\hline HT & THE & 0.4064 \\
\hline HL & THL & 0.1755 \\
\hline HL & VAM & -0.0273 \\
\hline
\end{tabular}

\begin{tabular}{|c|c|c|}
\hline Net & $\begin{array}{c}\text { Station } \\
\text { Code }\end{array}$ & $\boldsymbol{d}_{\boldsymbol{i}}$ \\
\hline HA & VILL & -0.1367 \\
\hline HL & VLI & 0.0213 \\
\hline HL & VLS & 0.0842 \\
\hline HP & VLX & -0.1923 \\
\hline HL & VLY & -0.0486 \\
\hline HT & XOR & -0.0255 \\
\hline HL & ZKR & 0.1078 \\
\hline HP & ZKS & -0.3141 \\
\hline
\end{tabular}

The final graph representing the dependence of $M_{w}-\log A_{0}$ upon the hypocentral distance, $R$, is given in Figure 4. The hypocentral distances are up to $\sim 550 \mathrm{~km}$ while the parameters best fitting the relation 2 are $n=1.2328$ (geometrical spreading), $K=0.0031$ (anelastic attenuation) and $c=3.1465$, with high correlation $(R=0.9247)$. These values can be considered as representative for Greece and surrounding areas since they are based on data of earthquakes with epicenters satisfactorily covering this area. The respective values for the area of southern California (Hutton and Boore, 1987) are $n=1.11$ and $K=0.00189$. Figure 5 shows that the formed calibration function fits well the data of each one of the four contributing networks (HL, HT, HP and HA).

Comparison of these two curves shows (Figure 6) that while the attenuation in Greece is slightly weaker than that of southern California for hypocentral distances up to $\sim 100 \mathrm{~km}$, it becomes clearly stronger for distances between 100 and $550 \mathrm{~km}$.

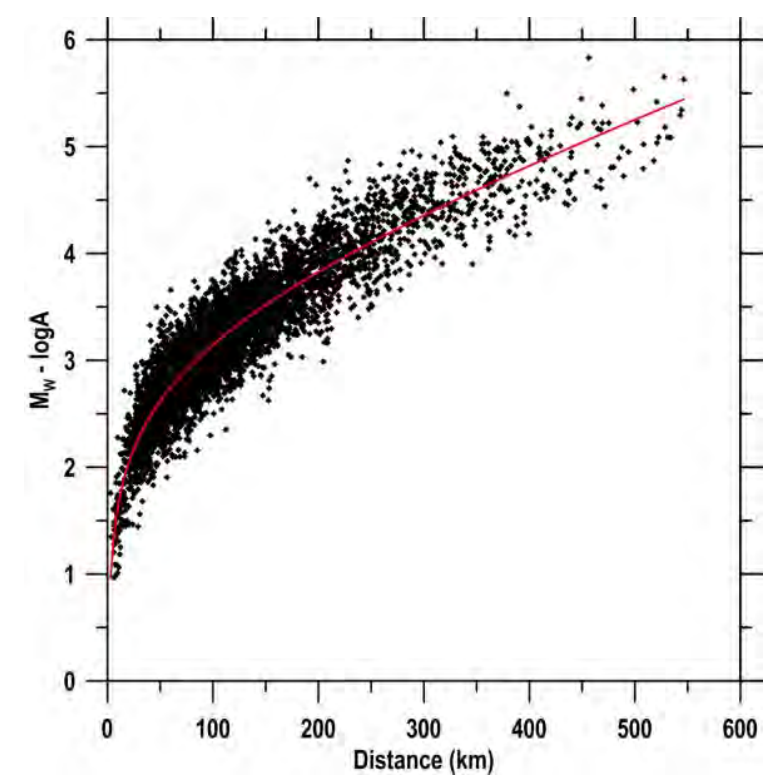

Figure 4- Calibration function for shallow $(h<40 \mathrm{~km})$ earthquakes after applying the stations' corrections listed on table 1 . The line represents the best fitting the data curve.

$\underline{\text { XLVII, No } 3-1246}$ 
A data-set consisting of amplitude readings of recent earthquakes which occurred in the broader Aegean area within the year 2012 was used to check the consistency of $M_{W}$ with the $M_{L}$ estimated by the relation proposed in the present study. This data-set is completely independent since it didn't participate in geometrical spreading factor and anelastic attenuation parameter estimation and, therefore, it can be used to test new relation's reliability. Thus, using the values of parameters $n, K, c$ and $d_{i}$ in relation 2, the average magnitude for each of these events was re-calculated and its consistency with the respective moment magnitude (only earthquakes with at least two reported $M_{w}$ values were used to strengthen test reliability) was checked (Figure 7a). Despite the small number of the available pairs (77) and the lack of enough $M_{W}$ GCMT observations, the regression analysis showed clear linearity expressed by the relation $M_{W}=M_{L}+0.04$, with high correlation $(R=0.94)$ and low standard deviation $(\sigma=0.18)$. Clear equivalence of these two magnitude scales is also revealed by using $192 M_{W} / M_{L}$ pairs concerning earthquakes of the time period 2007-2011 $\left(M_{W}=M_{L^{-}} 0.003, R=0.96, \sigma=0.17\right.$, Figure $\left.7 \mathrm{~b}\right)$. This objective test shows clear equivalency between the original $M_{W}$ and the $M_{L}$ derived from the relation proposed in the present study, for a wide range of values $(\sim 3.5-6.5)$. The high correlation can be attributed to the good quality of readings of digital recordings, to the stable behavior of the digital sensors and to the robustness of the geometrical spreading factor and anelastic attenuation coefficient, defined in the present study.
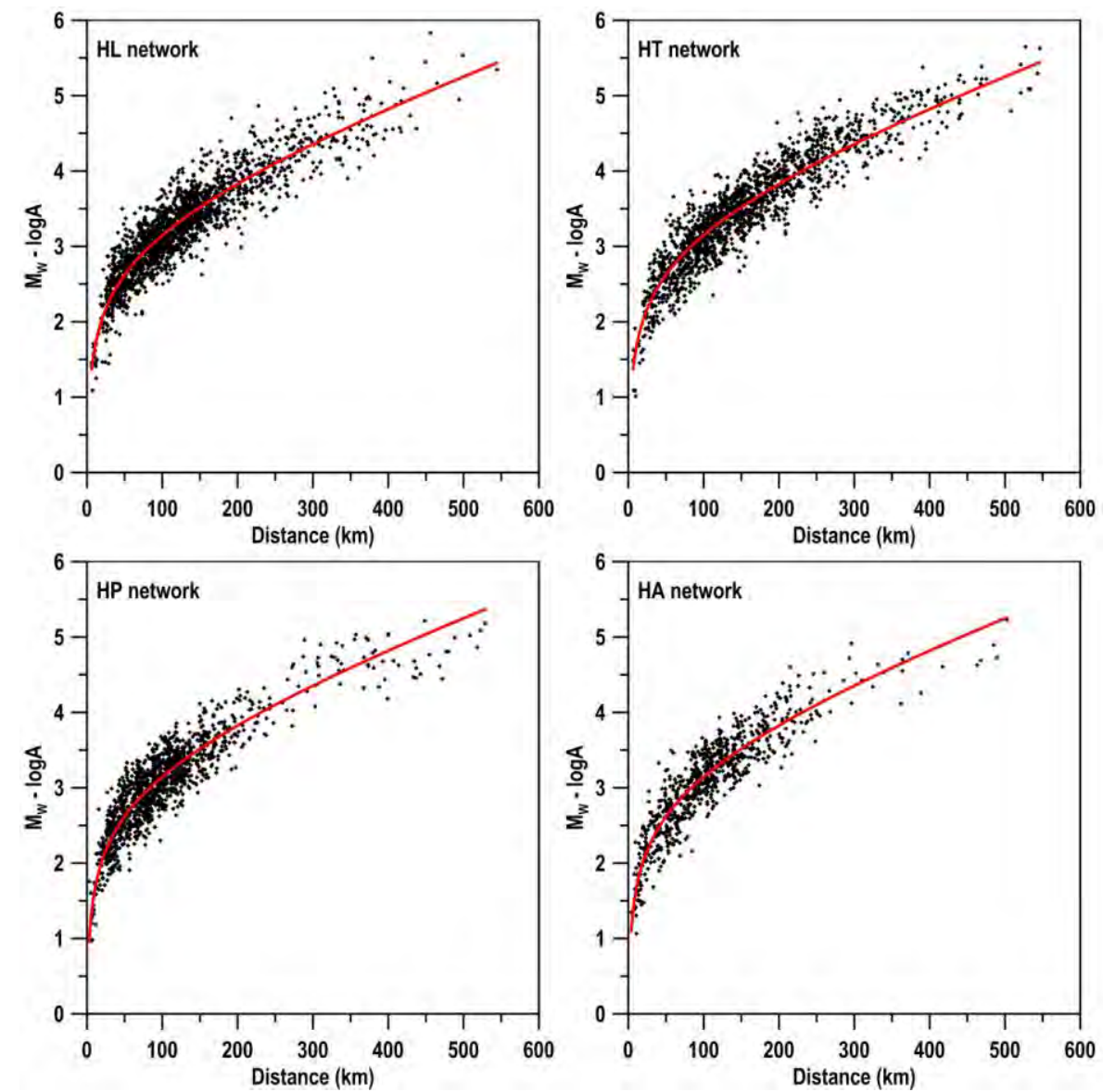

Figure 5 - Plot of $M-\log A$ versus hypocentral distance for the stations of each one of the four participating networks (the lines represent the final calibration function defined in the present work).

$\underline{\text { XLVII, No } 3 \text { - } 1247}$ 


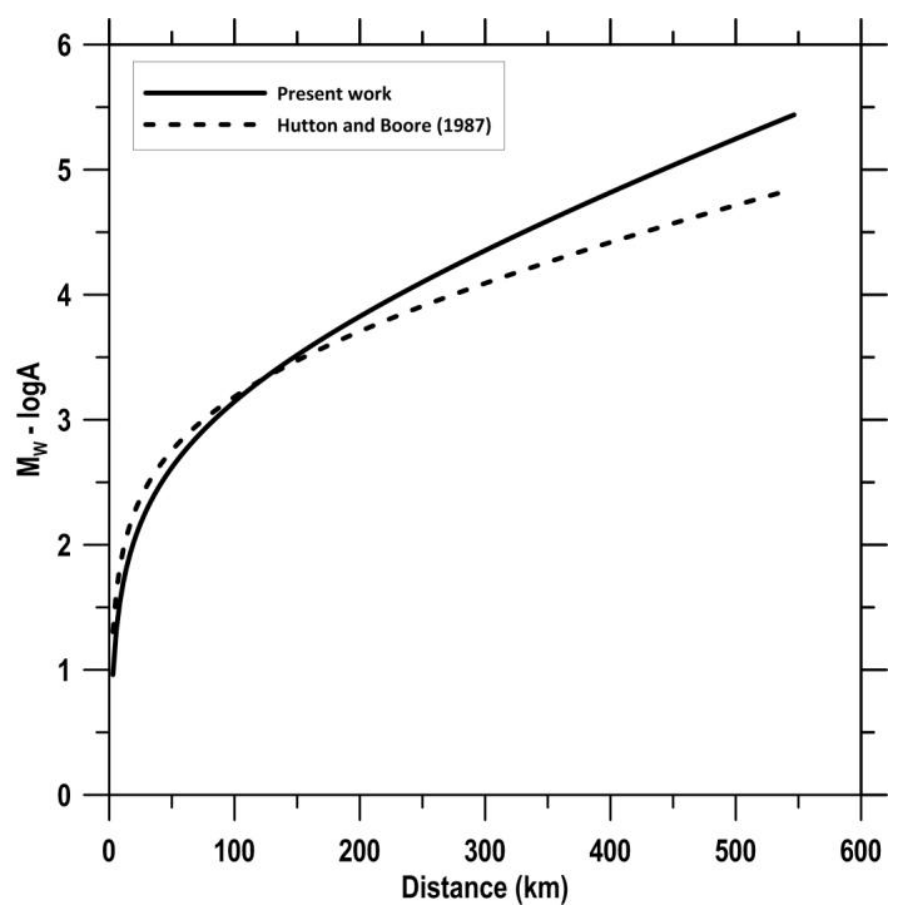

Figure 6 - Comparison of calibration functions for Greece (defined in the present work, solid line) with that (dashed) for southern California (Hutton and Boore, 1987).
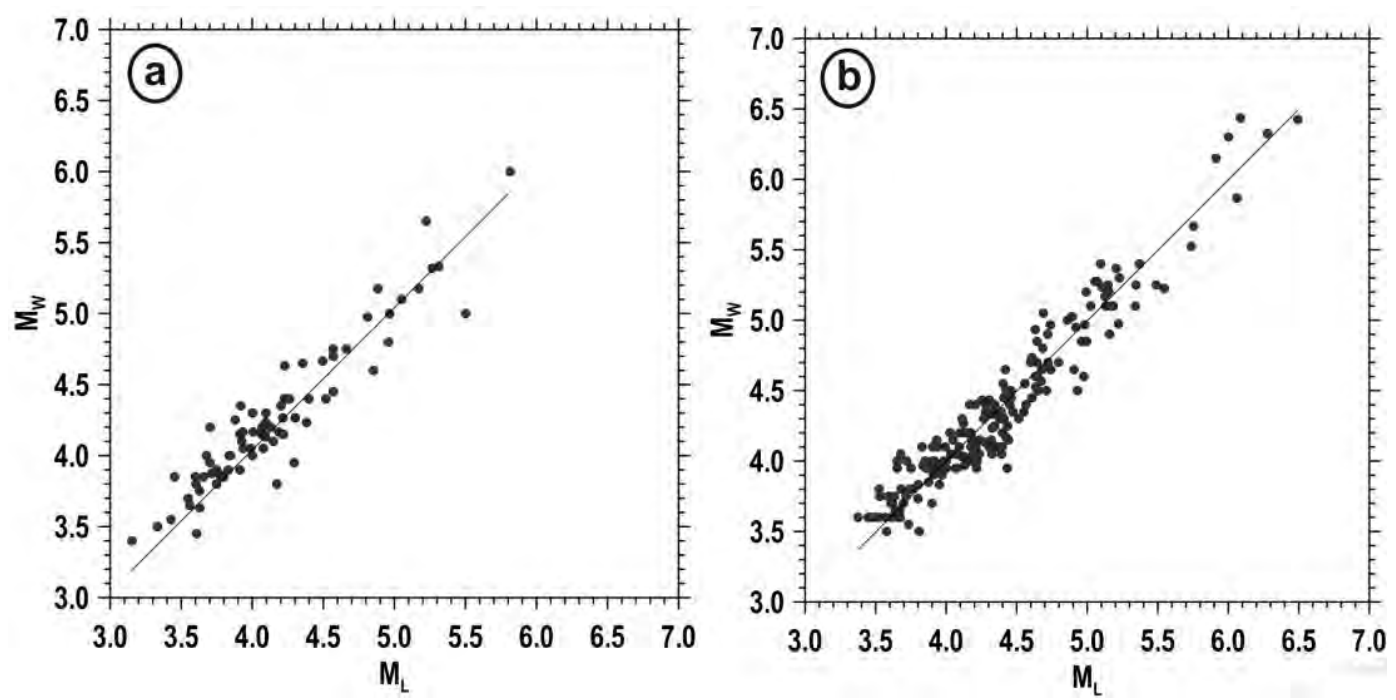

Figure 7 - Comparison between original $M_{W}$ and $M_{L}$ estimated by relation 2 of this work for two data-sets: a) independent data-set (2012) used to test new relation's reliability and b) main data-set (2007-2011) used for new geometrical spreading factor and anelastic attenuation parameter estimation. Straight lines represent the lines best fitting the data, in the leastsquares' sense. 


\section{Conclusions}

The goal of the present work is to define new reliable attenuation parameters and station-level corrections for local magnitude estimation in Greece based on reliable recordings of digital broadband instruments of the HUSN. For this reason an adequate amount of high quality data has been used assuring the robustness of the result.

Amplitude readings measured on synthetic Wood-Anderson (SWA) recordings produced by digital broad-band instruments, form our data-tank. Only records that correspond to shallow earthquakes (focal depths up to $40 \mathrm{~km}$ ) which occurred in Greece and surrounding areas during the time-period October 2007 - December 2011 are considered.

Both geometrical spreading and anelastic attenuation were examined. The finally estimated parameters, $n=1.2328$ for the geometrical spreading factor, $K=0.0031$ for the anelastic attenuation coefficient and $c=3.1465$ for the correction term, were used in order to define leveling correction corresponding to each station (tables 3 and 4). It is obvious that geometrical spreading plays the main role while anelastic attenuation is rather negligible. Comparison of the derived calibration function with that of southern California, defined by Hutton and Boore (1987), shows slightly weaker attenuation in Greece for hypocentral distances up to $\sim 100 \mathrm{~km}$, but noticeably stronger for distances between 100 and $550 \mathrm{~km}$.

Comparison of the magnitudes, $M_{L}$, which are estimated by the relation proposed in this study, with original $M_{W}$ (Figure 7) for two data-sets, one of recent earthquakes (not used to produce the relation) and a second one with earthquakes occurred during 2007-2011, shows that these two magnitude scales are equivalent with high correlation coefficients $(R=0.94$ and $R=0.96$, respectively), for a wide range of magnitudes.

The proposed relation can be used in the routine analyses for reliable estimation of earthquake magnitudes in Greece. It can be also used to create homogeneous earthquake catalogs with reliable magnitudes accurately estimated and expressed in a common and widely used scale such as the local magnitude scale.

\section{Acknowledgments}

The maps were produced with the GMT software (Wessel and Smith, 1995). This research has been co-financed by the European Union (European Social Fund - ESF) and Greek national funds through the Operational Program "Education and Lifelong Learning" of the National Strategic Reference Framework (NSRF) - Research Funding Program: THALES. Investing in knowledge society through the European Social Fund. Project SEISMO FEAR HELLARC. Geophysics Department Contribution Number 807/2013.

\section{References}

Anderson J.A. and Wood H.O. 1924. A torsion seismometer, J. Opt. Soc. Am. Rev. Sci. Inst., 8, 81 $7-822$.

Anderson J.A. and Wood H.O. 1925, Description and theory of the torsion seismometer, Bull. Seis m. Soc. Am., 15, 1-72.

Bakun W.H. and Joyner W.B. 1984. The $\mathrm{M}_{\mathrm{L}}$ scale in central California, Bull. Seism. Soc. Am., 74, $1827-1843$.

Bakun W.H., Houck S.T. and Lee W.H.K. 1978. A direct comparison of "synthetic" and actual Wo od-Anderson seismograms, Bull. Seism. Soc. Am., 68, 1199-1202.

Bollinger G.A., Chapman M.C. and Sibol M.S. 1993. A comparison of earthquake damage areas a s a function of magnitude across the United States, Bull. Seim. Soc. Am., 83, 1064-1080.

Boore D.M. 1989. The Richter scale: its development and use for determining earthquake source parameters, Tectonophysics, 166, 1-14.

$\underline{\text { XLVII, No } 3-1249}$ 
Brazier R.A., Miao Q., Nyblade A.A., Ayele A. and Langston C.A. 2008. Local magnitude scale for the Ethiopian Plateau, Bull. Seism. Soc. Am., 98, 5, 2341-2348.

Fletcher R. 1970. A new approach to variable metric algorithms, Comput. J., 7, 308-313.

Grünthal G. and Wahlström R. 2003. An $M_{W}$ based earthquake catalogue for central, northern and northwestern Europe using a hierarchy of magnitude conversions, J. Seismol., 7(4),507-531.

Hanks T. and Kanamori H. 1979. A moment magnitude scale, J. Geophys. Res., 84, 2348-2350.

Heaton T., Tajima F. and Mori A. 1986. Estimating ground motions using recorded accelerograms, Surv. Geophys. 8, 25-83.

Hutton L.K. and Boore D.M. 1987. The $\mathrm{M}_{\mathrm{L}}$ scale in southern California, Bull. Seism. Soc. Am., 77 , 2074-2094.

James R. 1998. MINUIT: Function minimization and error analysis, Reference Manual, Ver 94.1, CERN Geneva, Switzerland, 54pp.

Johnston A.C. 1996. Seismic moment assessment of earthquakes in stable continental regions-I. Instrumental seismicity, Geophys. J. Int., 124, 381-414.

Kanamori H. 1977. The energy release in great earthquakes, J. Geophys. Res., 82, 2981-2987.

Kanamori H. and Jennings P.C. 1978. Determination of local magnitude, $\mathrm{M}_{\mathrm{L}}$, from strong motion accelerograms, Bull. Seism. Soc. Am., 68, 471-485.

Kim W.Y., Wahlström R. and Uski M. 1989. Regional spectral scaling relations of source paramet ers for earthquakes in the Baltic Shield, Tectonophysics, 166, 151-161.

Kiratzi A.A. 1984. Magnitude scales for earthquakes in the broader Aegean area, Ph.D. Thesis, Aristotle University of Thessaloniki, $189 \mathrm{pp}$.

Kiratzi A.A. and Papazachos B.C. 1984. Magnitude scales for earthquakes in Greece, Bull. Seism. Soc. Am., 74, 969-985.

Margaris B.N. and Papazachos C.B. 1999. Moment-magnitude relations based on strong-motion re cords in Greece, Bull. Seism. Soc. Am., 89, 442-455.

Nelder J.A. and Mead R. 1965. A simplex method for function minimization, Comput. J., 7, 308-3 13.

Papazachos B.C., Kiratzi A.A. and Karakostas B.G. 1997. Toward a homogeneous momentmagnitude determination for earthquakes in Greece and surrounding area, Bull. Seism. Soc. Am., 87, 474-483.

Papazachos B.C., Karakostas V.G., Kiratzi A.A., Margaris B.N., Papazachos C.B. and Scordilis E. M. 2002. Uncertainties in the estimation of earthquake magnitudes in Greece, J. Seismol., 6, 557-570.

Richter C. 1935. An instrumental earthquake magnitude scale, Bull. Seism. Soc. Am., 25, 1-32.

Richter C.F. 1958. Elementary Seismology, W.H. Freeman, San Francisco, 578pp.

Scordilis E. 1985. A microseismicity study of the Serbomacedonian zone and the surrounding area ,Ph.D. Thesis, University of Thessaloniki, $250 \mathrm{pp}$.

Scordilis E.M. 2006. Empirical global relations converting $\mathrm{M}_{\mathrm{S}}$ and $\mathrm{m}_{\mathrm{b}}$ to moment magnitudes, $J$. Seismology, 10, 225-236.

Shedlock K.M. 1999. Seismic hazard map of North and Central America and the Caribbean, Ann. Geofis., 42, 977-997.

Uhrhammer R. and Collins E. 1990. Synthesis of Wood Anderson seismograms from broadband digital records, Bull. Seism. Soc. Am., 80, 702-716.

Uhrhammer R.A., Loper S.J. and Romanowicz B. 1996. Determination of local magnitude using B DSN broadband records, Bull. Seism. Soc. Am., 86, 1314-1330.

Utsu T. 2002. Relationships between magnitude scales, International Handbook of Earthquake an d Engineering Seismology, 81, 733-746.

Wahlström R. and Grünthal G. 2000. Probabilistic seismic hazard assessment (horizontal PGA) for Sweden, Finland and Denmark using different logic tree approaches, Soil Dyn. Earthq. Eng., 20, 45-58.

Wessel P. and W. Smith 1995. New version of the Generic Mapping Tools, EOS, 76, 329. 